\title{
RESEARCH
}

\section{Response Of Hybrid Oregon Lily Physical Process To The Date Of Stem Cutting Off}

\author{
Prof. Krishna Gautam
}

Department Of Botany Tribhuvan University Nepal

\begin{abstract}
The impact of various stem cutting off date on the event of underground organs significantly bulb lets of 4 liliaceous plant hybrids was investigated. 3 treatments were used enclosed the bulbs weren't removed (control) or removed half-dozen and eight weeks once planting . The check hybrids were "Royal show" (LA hybrids), "White heaven" (L. long iflorum hybrid), "Sorbonne" and "Premium blond" (Oriental hybrids).The results indicated that the event of underground organs of plant was greatly influenced by stem removal. However, both 6, eight weeks treatments considerably magnified the stem production compared to regulate treatment, however eight weeks treatment recorded the best production. The six weeks treatment had stronger induced impact on the emerged shoots from bulb lets. The hybrid Oregon lily differed considerably for all ascertained traits. However, the "Royal show" variety recorded the best values of stem range and weight. The "White heaven" variety showed the most effective capability of the shoots emergence from the stem and from the daughters that fully grown within the mother bulbs. each "Sorbonne" and "Premium blond" cultivars had a lot of growth of stem roots, less stem, no emerged shoots, compared to alternative cultivars. of these observations recommend that the technique of stem cutting off have a possible use to stimulate the plant to provide a lot of stem and also the tested hybrids of Oregon lily showed important variations in their capability for stem formation and in their response to stem removal.
\end{abstract}

Key words: Hybrid Oregon lily, underground organs, stem cutting off date,

\section{Introduction}




\section{THE AMERICAN JOURNAL OF}

\section{RESEARCH}

Oregon lily manufacture terribly enticing flowers with a large vary of significant studies associated with geophytes were carried colors, shapes so they create glorious cut flowers, dead set investigate the link between the stem and tremendous flowering potted plants and a nice plant development, and to know the most changes decorative worth for landscape functions. However, the in this relationship throughout totally different stages of plant vital teams of hybrid Oregon lily for cut flower production development, these studies indicated that the stem is area unit Asiatic hybrids, LA hybrids (they area unit a cross between vital supply which offer macromolecule reserves for $L$. longiflorum and Asiatic lily), oriental hybrids and growth and physical process of the plant significantly in early longiflorium hybrids (L. longiflorum). These teams have stages, and also the flowers area unit thought of as major organ several things in common however there area unit some variations utilizes and consumes the carbohydrates that received between them; some connected to their morphological, from current chemical process and stem scales (Addai and anatomical structures and organic process patterns, whereas Scott, 2011a, b; Wu et al., 2012b). The recent study (Wu others connected to their growing and environmental et al., 2012a) confirmed that the stems taken into account as a conditions .sink dependently on the stages of plant development.

\section{Materials and ways}

This experiment was conducted within the nursery of horticulture Unit, Bagdad University, Asian nation in Gregorian calendar month 2012 to March 2013. Vernalized bulbs of 4 liliaceous plant hybrids together with "Royal show"

represents LA hybrids cluster, "White heaven", represents L. longiflorum hybrid cluster , "Sorbonne" and "Premium blond"

represent oriental hybrids cluster (10 to fourteen $\mathrm{cm}$ in circumference) were foreign from European nation. The bulbs were planted within the plastic house of the nursery in cultivation beds containing peat moss (peat-moss was obtained from Estonia; kind $\mathrm{H} 2-4$, ) and contains $\mathrm{N}$ : P: $\mathrm{K}$ - 14:16:18 fertilizer, lime, with hydrogen ion concentration worth of (5.9). Planting was at seven $\mathrm{cm}$ depth with twenty $(\mathrm{cm})$ apart to push physical process of stem roots, and also the irrigation was manually. to get rid of the stem from the plant, the stem was interrupt fastidiously higher than the nose of the stem with none impact to stem roots. The plant was re-planted once more directly once the stem was removed. The dates of stem cutting off were half-dozen weeks and 


\section{THE AMERICAN JOURNAL OF}

\section{RESEARCH}

eight weeks once planting. The management treatment consisted of plants whose bulbs weren't removed.

\section{Stem roots}

The weight of stem roots (g) per plant was totally different as keen about cutting off treatments and cultivars (Table five and Figure 1). It varied from zero.00 to 26.37 (g) among the treatments. However, the plants of management treatment showed a lot of stem roots compared to the plants of cutting off treatments. the load of stem roots differed considerably among the tested hybrids of Oregon lily . it had been considerably higher in "Sorbonne" variety and lower in "White heaven" variety compared to alternative cultivars.

\section{Stem}

The weight (g) of stem per plant was totally different as keen about growth stage and cultivars (Table 6). It varied from eighteen.26 to $83.74 \mathrm{~g}$. However, it had been considerably higher once eighteen weeks of planting and lower once half-dozen and eight weeks of planting compared to stem weight before planting all told cultivars. Four hybrids of Oregon lily showed important variations in stem weight once eighteen weeks of planting which the "Sorbonne" variety had larger stem compare to others

\section{Discussion}

The results indicated that the event of underground organs of plant were greatly tormented by stem cutting off treatments which most likely thanks to cutting off of stem leading to loss of the foremost sink for macromolecule which caused the carbohydrates to remobilize and to accumulate into alternative underground organs, both 6 , eight weeks treatments considerably magnified the stem production compared to regulate treatment, however eight weeks treatment recorded the best production, which most likely thanks to the plants of half-dozen weeks 


\section{THE AMERICAN JOURNAL OF}

\section{RESEARCH}

treatment and also the plants of eight weeks treatment were in several physical process stages once the bulbs were removed and it means, they'd totally different relationship of supply - sink, as a result of this relationship amendment throughout plant physical process (Addai and Scott, 2011a, b; Wu et al., 2012a, b). Six weeks treatment created considerably a lot of emerged shoots from stem compared to alternative treatments. the load of stem was lower once half-dozen and eight weeks of planting however it had been higher once eighteen weeks of planting compared to stem weight before planting which most likely thanks to the plants once half-dozen, eight weeks of planting were in stage

The results conjointly indicated that the tested cultivars behaved otherwise in term of the event of underground organs and marked variations were ascertained among them just in case of their response to cutting off treatments. However, the "Royal show" variety had a lot of stem however with no shoots. The "White heaven" variety showed a lot of emerged shoots from stem female offspring and from stem. The "Sorbonne" and "premium blond " cultivars had less stem with no shoots, however a lot of stem roots with giant bulbs that contain large daughters compared to alternative cultivars which most likely thanks to the plants of "Sorbonne" and "premium blond " hold on their macromolecule reserves chiefly into the stem daughters and stem roots instead of into stem whereas the plants of "White heaven" and "Royal show" cultivars were greatly allotted their energy into the stem and shoots.

\section{References}

Addai IK, Scott P (2001a). Regulation of carbohydrates partitioning and metabolism of the hyacinth. Agric. Biol. J. North Am.

Leclerc MC, author CD, Rajasekaran LR, Norrie J (2010). impact of inflorescence cutting offend propagates formation of herbaceous plant $x$ arendsii, Hemerocallis spp and Hosts spp.

Rohm MS (2012). Controlled flowering within the Genus Cilium- Review of the past achievements and also the future direction of analysis.

Wu SS, Chen LN, Zhang QX, cardinal YM ( 2010a). supply and sink changes of liliaceous plant stead also the transportation role of the basal plate throughout the event of oriental hybrid liliaceous plant 'Sorbonne'. J. Food. Agric.-1219 